\title{
Antimicrobial therapy and assessing therapeutic response in culture-negative pyogenic vertebral osteomyelitis: a retrospective comparative study with culture-positive pyogenic vertebral osteomyelitis
}

\author{
Dongwoo Yu, Sang Woo Kim and Ikchan Jeon *i]
}

\begin{abstract}
Background: There are still controversies regarding the treatment and outcomes in culture-negative pyogenic vertebral osteomyelitis (PVO). The purpose of this study is to investigate the antimicrobial therapy, assessment of therapeutic response, and outcome of culture-negative PVO compared to culture-positive PVO.

Methods: A retrospective study was performed with non-surgical lumbar PVO patients. The patients were divided into two groups based on the causative bacterial identification (CN group with culture-negative PVO and CP group with culture-positive PVO). The clinical features, use of antibiotics, laboratory data, and outcomes were compared between the two groups.
\end{abstract}

Results: Seventy-three patients with 41 (56.2\%) of the CN group and 32 (43.8\%) of the CP group were enrolled. The CN group showed a shorter duration of parenteral antibiotics (45.88 \pm 16.14 vs. $57.31 \pm 24.39, p=0.019)$ but a tendency of prolonged duration of total (parenteral + oral) antibiotics (101.17 \pm 52.84 vs. $84.19 \pm 50.29$ days, $p=$ 0.168). When parenteral antibiotics were discontinued or switched to oral antibiotics, the mean erythrocyte segmentation rate (ESR, normal range: $<25 \mathrm{~mm} / \mathrm{h}$ ), C-reactive protein (CRP, normal range: $<0.5 \mathrm{mg} / \mathrm{dL}$ ) level, and visual analog scale (VAS) score of back pain were $42.86 \pm 24.05 \mathrm{~mm} / \mathrm{h}, 0.91 \pm 1.18 \mathrm{mg} / \mathrm{dL}$, and $4.05 \pm 1.07$, respectively, with no significant differences between the two groups. The recurrence rates of $C N$ and $C P$ groups were $7.3 \%(3 / 41)$ and $6.3 \%(2 / 32)$, respectively $(p=1.000)$. The presence of epidural abscess was the most significant factor for the identification of causative bacteria $(p=0.002)$, and there was no significant relationship between the use of empirical antibiotics before tissue culture and the causative bacterial identification $(p=0.194)$.

(Continued on next page)

\footnotetext{
*Correspondence: jicns@hanmail.net

Department of Neurosurgery, Yeungnam University Hospital, Yeungnam University College of Medicine, 170, Hyeonchung street, Nam-Gu, Daegu 42415, South Korea
}

C C The Author(s). 2020 Open Access This article is licensed under a Creative Commons Attribution 4.0 International License, which permits use, sharing, adaptation, distribution and reproduction in any medium or format, as long as you give appropriate credit to the original author(s) and the source, provide a link to the Creative Commons licence, and indicate if changes were made. The images or other third party material in this article are included in the article's Creative Commons licence, unless indicated otherwise in a credit line to the material. If material is not included in the article's Creative Commons licence and your intended use is not permitted by statutory regulation or exceeds the permitted use, you will need to obtain permission directly from the copyright holder. To view a copy of this licence, visit http://creativecommons.org/licenses/by/4.0/ The Creative Commons Public Domain Dedication waiver (http://creativecommons.org/publicdomain/zero/1.0/) applies to the data made available in this article, unless otherwise stated in a credit line to the data. 
(Continued from previous page)

Conclusions: The CN group required a shorter duration of parenteral antibiotics than the CP group.

Discontinuation of parenteral antibiotics or changing the administration route can be considered based on the

values of ESR, CRP, and VAS score of back pain. The presence of epidural abscess was the most significant factor for the identification of causative bacteria.

Keywords: Vertebral osteomyelitis, Pyogenic, Negative culture, Antibiotics, Lumbar

\section{Background}

Vertebral osteomyelitis is an infectious disease that can develop by pyogenic, tuberculous, or brucellar causes [1]. The annual incidence of hospitalization with pyogenic vertebral osteomyelitis (PVO) in the United States between 1998 and 2013 rose from 2.9 to 5.4 per 100,000 individuals [2]. There is still no clear guidance regarding the duration and route of antibiotic administration. Generally, an extended course of parenteral antibiotics followed by a maintenance course of oral antibiotics is required in the treatment of PVO [3-5]. Infectious Diseases Society of America (IDSA) recommends 6 weeks of parenteral or highly bioavailable oral antimicrobial therapy for bacterial native vertebral osteomyelitis [6].

Identification of the causative bacteria and the use of appropriate antibiotics are necessary to achieve successful treatment and favorable outcomes in PVO. Despite a lot of effort, it is not always possible to identify the causative microorganism in clinical practice. About 50\% of patients with PVO are treated with empirical antibiotics because PVO often shows negative in the microbiological culture test $[7,8]$. The guidelines for the choice and preferred route of antibiotic administration for culture-negative PVO have not been well established owing to insufficient relevant research result, which is originated in the variety of causative microorganisms and rate of antibiotic resistance depending on the regions. Herein, we conducted a retrospective study to compare culture-negative PVO and culture-positive PVO in terms of clinical characteristics, use of antibiotics, assessment of therapeutic response, and outcomes.

\section{Methods}

\section{Patients and data collection}

This retrospective study was performed at a single tertiary-care university hospital from October 2014 to September 2018 and included 118 patients diagnosed as pyogenic lumbar PVO. Patients were excluded if they had tuberculous spondylitis, tumors, postoperative development, accompanying bone infection at another site, trauma, pregnancy, concomitant severe medical problems, less than six months of follow-up period, or age $<19$ years. All clinical and radiological data were obtained and reviewed retrospectively from electronic charts under the approval of the institutional review board (Yeungnam University Hospital, 2020-06-091).

\section{Diagnosis of PVO}

PVO was diagnosed based on clinical symptoms, laboratory data, and radiological findings. The clinical symptoms included fever and back pain with or without radiating pain. Elevated erythrocyte segmentation rate (ESR, normal range: $<25 \mathrm{~mm} / \mathrm{h}$ ) or C-reactive protein (CRP, normal range: $<0.5 \mathrm{mg} / \mathrm{dL}$ ) level or both along with specific magnetic resonance (MR) findings of PVO as a contiguous single lesion was an important clue for the diagnosis of PVO. In the extent of PVO lesion, a PVO lesion comprises the upper and lower vertebrae centering on the infected disc with or without epidural, psoas, and paraspinal abscesses; it was defined as one level (e.g., if there were two infected discs, then three vertebrae were included centering on the two infected discs, this PVO lesion was considered two levels) [9] .

\section{Causative bacterial identification}

Patients diagnosed as PVO were divided into two groups according to the results of causative bacterial identification. The microbiological diagnosis was confirmed through more than two sets of blood culture or tissue culture for the PVO lesion by computed tomography (CT)-guided needle biopsy or open surgical biopsy [10]. Patients with clinical symptoms and radiological findings indicative of PVO but without a confirmed causative bacterial identification were defined as the culturenegative group (CN group), and other patients in whom the causative microorganism was identified were defined as the culture-positive group (CP group).

\section{Cure and recurrence}

The patients underwent clinical assessment for therapeutic response after at least three weeks of parenteral antibiotic therapy, which was performed based on clinical symptoms (fever and back pain) and hematological inflammatory indices (CRP and ESR). The condition of being 'Cured' was defined as the absence of fever and resolution in back pain and improvement of CRP level, which continued during a follow-up period of at least six months without any other evidence of residual or 
recurrence of PVO. When a patient was determined as 'Cured' on clinical assessment for therapeutic response, antibiotic therapy was discontinued. The condition of being 'Non-cured' was defined as follows: persistence or re-aggravation of clinical symptoms and hematological indicies with the presence of fever and/or reidentification of same causative bacteria from blood/ PVO lesion and the development of new or reaggravation of the PVO lesion on MR imaging after discontinuation of antibiotic therapy within the followup period of at least six months $[11,12]$.

\section{Functional and laboratory evaluations}

All patients underwent the evaluation of clinical status and laboratory tests for the initial three months after the diagnosis of PVO and on starting antibiotic therapy. Visual analog scale (VAS) scores for back pain and laboratory data, including ESR and CRP at initial (at the time of diagnosis), 1 week, 1 month, and 3 months were compared between the two groups. VAS was used to estimate back pain, with 0 representing no pain to 10 representing maximum pain. The values of ESR and CRP when parenteral antibiotics were discontinued or switched to oral antibiotics were measured and compared between the two groups.

\section{Statistical analysis}

The Student's t-test and the Mann-Whitney U test were used to compare parametric and non-parametric continuous variables, respectively. One-way analysis of variance (ANOVA) for parametric continuous variables and the Kruskal-Wallis test for non-parametric continuous variables were used to compare three population means. For categorical variables, the chi-square test was performed. Logistic regression analysis was used to investigate the clinical variables related to the identification of causative microorganisms. All clinical variables identified as statistically significant in univariate analyses were included in a multivariate analysis. Statistical analysis was carried out using SPSS version 25.0 software (SPSS Inc., Chicago, Illinois), and $p$ values of $<0.05$ were considered statistically significant.

\section{Results}

\section{Demographic and clinical data}

Among the 118 patients, 45 were excluded due to surgery-related development $(n=25)$, tuberculosis $(n=$ $12)$, ankylosing spondylitis $(n=2)$, and follow-up loss $(n=6)$. The final analyses were performed on 73 patients (44 men and 29 women) with a mean age of $64.73 \pm$ $11.61(42-84)$ years. There were no statistically significant differences in age, gender, underlying diseases, and history of spinal procedures between the two groups. However, there were statistically significant differences in the extent of affected PVO lesion [1.49 \pm 0.93 (1-5) vs. $2.09 \pm 1.28(1-5)$ levels, $p=0.022]$ and the presence of epidural abscess $(43.9 \%$ [18/41] vs. $84.4 \%$ [27/32], $p=$ 0.001 ), except the presence of psoas muscle and paraspinal abscess. The recurrence rates were $7.3 \%(3 / 41)$ and $6.3 \%(2 / 32)$, respectively $(p=1.000)$. Detailed data are mentioned in Table 1.

\section{Microorganisms and antibiotics}

The rate of causative bacterial identification was only $43.8 \%(32 / 73)$ with 8 (25\%) from blood culture, 15 (46.9\%) from tissue culture of CT-guided needle or open surgical biopsy of the PVO lesion, and 9 (28.1\%) from both blood and tissue cultures. According to the culture methods, 17 of 73 patients (23.3\%) with blood cultures, 7 of 37 patients (18.9\%) with CT-guided needle biopsy, and 17 of 36 patients (47.2\%) with open surgical biopsy were identified. Microbiologic findings of the 32 patients in the $\mathrm{CP}$ group are shown in Table 2. The most common causative microorganism was Staphylococcus aureus $(40.6 \%, 13 / 32)$. Five cases of recurrence were noted: one with methicillinresistant Staphylococcus epidermidis, one with Enterobacter, and three with culture-negative cases. Detailed data are mentioned in Table 2.

The antibiotic regimens for the treatment of PVO are summarized in Table 3. $\beta$-Lactam and glycopeptide were the mainly used as the effective antibiotics in both groups. The use of glycopeptide did not significantly differ between the two groups. However, quinolones were used statistically significantly more in the $\mathrm{CN}$ group $(22.0 \%[9 / 41]$ vs. $3.1 \%[1 / 41], p=0.036)$. Antibiotics were administered before tissue culture of the PVO lesion in $71.2 \%$ cases $(52 / 73)$, and there was no significant difference between the two groups $(78.0 \%[32 / 41]$ vs. $62.5 \%$ [20/32], $p=0.194)$. There was no statistically significant difference in the duration of total antibiotics between the two groups $(101.17 \pm 52.84$ of $\mathrm{CN}$ group vs. $84.19 \pm$ 50.29 days of $\mathrm{CP}$ group, $p=0.168$ ). However, there were statistically significant differences in the duration of parenteral antibiotics $(45.88 \pm 16.14$ vs. $57.31 \pm 24.39, p=$ $0.019)$, oral antibiotics $(55.29 \pm 47.40$ vs. $26.84 \pm 41.10$, $p=0.009)$, and the incidence of using oral antibiotics (75.6\% [31/41] vs. $43.8 \%[14 / 32], p=0.001)$ between the two groups, respectively. Detailed data are provided in Table 4.

The clinical variables related to the causative bacterial identification are presented in Table 5. The clinical variables with statistical significance identified in a univariate logistic regression analysis were included in a multivariate logistic regression analysis. Epidural abscess and initial VAS score of back pain were statistically significant predictors. 
Table 1 Demographic and clinical data

\begin{tabular}{|c|c|c|c|c|}
\hline & $\mathrm{CN}$ group $(n=41)$ & CP group $(n=32)$ & $p$ value $^{\text {a }}$ & Total $(n=73)$ \\
\hline Age [year] & $65.41 \pm 11.60$ & $61.83 \pm 13.76$ & 0.570 & $64.73 \pm 11.61(42-84)$ \\
\hline Male sex & 27 (65.9\%) & $17(53.1 \%)$ & 0.337 & $44(60.3 \%)$ \\
\hline BMI & $22.97 \pm 3.25$ & $24.27 \pm 3.75$ & 0.120 & $23.54 \pm 3.52$ \\
\hline \multicolumn{5}{|l|}{ Underlying disease } \\
\hline Diabetes mellitus & $14(34.1 \%)$ & $7(21.9 \%)$ & 0.304 & $21(28.8 \%)$ \\
\hline Rheumatic disease & $3(7.3 \%)$ & $1(3.1 \%)$ & 0.626 & $4(5.5 \%)$ \\
\hline Liver cirrhosis & $2(4.9 \%)$ & $0(0 \%)$ & 0.501 & $2(2.7 \%)$ \\
\hline Chronic kidney disease & $1(2.4 \%)$ & $0(0 \%)$ & 1.000 & $1(1.4 \%)$ \\
\hline Alcohol & $13(31.7 \%)$ & $4(12.5 \%)$ & 0.092 & $17(23.3 \%)$ \\
\hline Smoking & $15(36.6 \%)$ & $6(18.8 \%)$ & 0.121 & $21(28.8 \%)$ \\
\hline History of spinal procedures & $27(65.9 \%)$ & $18(56.3 \%)$ & 0.471 & $45(61.6 \%)$ \\
\hline Epidural injection & $25(55.6 \%)$ & $18(50.0 \%)$ & 0.659 & $43(53.1 \%)$ \\
\hline Acupuncture [oriental medicine] & $10(24.4 \%)$ & $4(12.5 \%)$ & 0.242 & $14(19.2 \%)$ \\
\hline Fever $\left[{ }^{\circ} \mathrm{C},>37.3\right]$ & $11(26.8 \%)$ & $8(25.0 \%)$ & 1.000 & $19(26.0 \%)$ \\
\hline Neurological symptom & $17(41.5 \%)$ & $20(62.5 \%)$ & 0.100 & $37(50.7 \%)$ \\
\hline \multicolumn{5}{|l|}{ Features of PVO } \\
\hline Extent of affected lesion [level] & $1.49 \pm 0.93(1-5)$ & $2.09 \pm 1.28(1-5)$ & 0.022 & $1.75 \pm 1.13(1-5)$ \\
\hline Epidural abscess & $18(43.9 \%)$ & 27 (84.4\%) & 0.001 & $45(61.6 \%)$ \\
\hline Psoas abscess & $17(41.5 \%)$ & $13(40.6 \%)$ & 1.000 & $30(41.1 \%)$ \\
\hline Paraspinal abscess & $27(65.6 \%)$ & $23(71.9 \%)$ & 0.612 & $50(68.5 \%)$ \\
\hline Duration of hospital stay [days] & $50.32 \pm 19.96(21-120)$ & $62.88 \pm 26.04(26-143)$ & 0.022 & $55.82 \pm 23.51(21-143)$ \\
\hline Follow up period [months] & $18.00 \pm 11.16(6-42)$ & $16.38 \pm 12.48(6-63)$ & 0.560 & $17.29 \pm 11.70(6-63)$ \\
\hline Recurrence & $3(7.3 \%)$ & $2(6.3 \%)$ & 1.000 & $5(6.8 \%)$ \\
\hline
\end{tabular}

Data are presented as the mean \pm standard deviation or frequency, $C N$ culture negative, $C P$ culture positive, $B M I$ body mass index, $P V O$ pyogenic vertebral osteomyelitis, ${ }^{a} p$ value between group $\mathrm{CN}$ and $\mathrm{CP}, p$ values of $<0.05$ were considered statistically significant.

\section{Changes of ESR/CRP and VAS score for back pain during the early 3-month after starting antibiotics}

There were statistically significant improvements in ESR, CRP, and VAS score of back pain in both groups during early 3 months, respectively $(p<0.01)$. In ESR, there were no statistically significant differences at initial, 1 week, 1 month, and 3 months findings between the two groups. However, there were statistically significant differences in CRP $(9.21 \pm 7.43$ vs. $15.17 \pm 10.32 \mathrm{mg} / \mathrm{dL}, p=$ $0.005)$ and VAS score of back pain (7.41 \pm 0.92 vs. $8.13 \pm 1.13, p=0.004)$ at initial assessment between the two groups, respectively. However, there were no statistically significant differences in CRP and ESR at 1-week, 1-month, and 3-month between the two groups, respectively. When parenteral antibiotics discontinued or changed to oral antibiotics, there were no statistically significant differences in ESR, CRP, and VAS score of back pain between the two groups. The values of ESR, CRP, and VAS score of back pain in total patients were $44.85 \pm 24.99 \mathrm{~mm} / \mathrm{h}, 0.89 \pm 1.02 \mathrm{mg} / \mathrm{dL}$, and $3.98 \pm 1.08$, respectively. Detailed data are provided in Table 6.

\section{Discussion}

The rate of causative bacterial identification varies as reported in the previous literatures $[7,11,13]$, and this study showed lower rate with less than $50 \%$ compared to other reports. The result is expected to be the most relevant to the use of empirical antibiotics before tissue culture for the PVO lesion $(52 / 73,71.2 \%)$ due to poor general conditions, including high fever or sepsis, although blood cultures were performed in all patients before administering empirical antibiotics. However, there was no statistically significant relationship between the use of empirical antibiotics before tissue culture and the causative bacterial identification (32/41 in $\mathrm{CN}$ group vs. $20 / 32$ in CP group, $p=0.194)$. There are still debates on the influence of empirical antibiotics before tissue culture on the microbiological diagnostic yield [14-17]. In addition, the rate of causative bacterial identification in PVO varies with the method of culture. Generally, the rate of positive-culture is higher with an open surgical biopsy than with needle biopsy, which is related to the obtaining sufficient specimen quantity from the accurate 
Table 2 Microbiologic findings

\begin{tabular}{|c|c|}
\hline Factors & Values \\
\hline Causative bacterial identification & $32 / 73(43.8 \%)$ \\
\hline Blood culture & $8(25.0 \%)$ \\
\hline Tissue culture of CT-guided needle biopsy on PVO lesion & $5(15.6 \%)$ \\
\hline Tissue culture of open biopsy on PVO lesion & $10(31.3 \%)$ \\
\hline Both (blood and tissue cultures) & $9(28.1 \%)$ \\
\hline \multicolumn{2}{|l|}{ Positive culture rates depending on the methods } \\
\hline Blood culture & $17 / 73(23.3 \%)$ \\
\hline Tissue culture of CT-guided needle biopsy on PVO lesion & $7 / 37(18.9 \%)$ \\
\hline Tissue culture of open biopsy on PVO lesion & $17 / 36(47.2 \%)$ \\
\hline \multicolumn{2}{|l|}{ Microbiological findings $(n=32)$} \\
\hline Gram-positive bacteria & $26(81.3 \%)$ \\
\hline Staphylococcus aureus & $13(40.6 \%)$ \\
\hline MSSA & $10(31.2 \%)$ \\
\hline MRSA & $3(9.4 \%)$ \\
\hline Coagulase-negative staphylococci & $4(12.5 \%)$ \\
\hline Streptococcus species & $6(18.8 \%)$ \\
\hline Streptococcus agalactiae & $2(6.3 \%)$ \\
\hline Others $^{\mathrm{a}}$ & $4(12.5 \%)$ \\
\hline Enterococcus species & $3(9.4 \%)$ \\
\hline Gram-negative bacteria & $6(18.8 \%)$ \\
\hline Escherichia coli & $2(6.3 \%)$ \\
\hline Klebsiella pneumoniae & $1(3.1 \%)$ \\
\hline Acinetobactor baumannii & $2(6.3 \%)$ \\
\hline Enterobacter species & $1(3.1 \%)$ \\
\hline
\end{tabular}

Data are presented as frequency, PVO pyogenic vertebral osteomyelitis, MSSA methicillin-sensitive Staphylococcus aureus, MRSA methicillin-resistant Staphylococcus aureus, ${ }^{a}$ Streptococcus viridians, Streptococcus pneumoniae, and Streptococcus bovis

Table 3 Regimens of antibiotics

\begin{tabular}{|c|c|c|c|c|}
\hline & CN group $(n=41)$ & CP group $(n=32)$ & $p$ value ${ }^{\#}$ & Total $(n=73)$ \\
\hline Parenteral antibiotics & $41(100 \%)$ & $32(100 \%)$ & - & $73(100 \%)$ \\
\hline$\beta$-Lactam & $15(36.6 \%)$ & $11(34.4 \%)$ & 1.000 & $26(35.6 \%)$ \\
\hline 1st generation cephalosporin & $10(24.4 \%)$ & $3(9.4 \%)$ & 0.128 & $13(17.8 \%)$ \\
\hline 3rd generation cephalosporin & $4(9.8 \%)$ & $2(6.3 \%)$ & 0.689 & $6(8.2 \%)$ \\
\hline Nafcillin & $1(2.4 \%)$ & $6(18.8 \%)$ & 0.039 & $7(9.6 \%)$ \\
\hline$\beta$-Lactam \pm others ${ }^{a}$ & $6(14.6 \%)$ & $5(15.6 \%)$ & 1.000 & $11(15.1 \%)$ \\
\hline Glycopeptide \pm others ${ }^{b}$ & $11(26.8 \%)$ & $12(37.5 \%)$ & 0.447 & $23(31.5 \%)$ \\
\hline Quinolone & $9(22.0 \%)$ & $1(3.1 \%)$ & 0.036 & $10(13.7 \%)$ \\
\hline Others $^{c}$ & $0(0 \%)$ & $3(9.4 \%)$ & 0.080 & $3(4.1 \%)$ \\
\hline Oral antibiotics & $33(77.8 \%)$ & $12(38.9 \%)$ & 0.001 & $49(60.5 \%)$ \\
\hline$\beta$-Lactam & $7(17.1 \%)$ & $1(3.1 \%)$ & 0.072 & $8(11.0 \%)$ \\
\hline Quinolone & $26(63.4 \%)$ & $11(34.4 \%)$ & 0.019 & $37(50.7 \%)$ \\
\hline
\end{tabular}

$C N$ culture negative, $C P$ culture positive, Data are presented as frequency, ${ }^{a} \beta$-lactamase inhibitor, aminoglycoside, ${ }^{\mathrm{b}}$ Gentamicin and tazime, ${ }^{\mathrm{C}} \mathrm{Carbapenem}$, prepenem, and linezoid, ${ }^{\#} p$ value between the $\mathrm{CN}$ and $\mathrm{CP}$ groups, $p$ values of $<0.05$ were considered statistically significant 
Table 4 Comparison of antibiotic treatment between the CN and CP groups

\begin{tabular}{lllll}
\hline & CN group $(\boldsymbol{n}=\mathbf{4 1})$ & CP group $(\boldsymbol{n}=\mathbf{3 2})$ & $\boldsymbol{p}$ value ${ }^{*}$ & Total $(\boldsymbol{n}=\mathbf{7 3})$ \\
\hline $\begin{array}{l}\text { Use of antibiotics before tissue-culture } \\
\text { Duration of antibiotic treatment (days) }\end{array}$ & $32 / 41(78.0 \%)$ & $20 / 32(62.5 \%)$ & 0.194 & $52 / 73(71.2 \%)$ \\
$\quad$ Total [parenteral + oral] & $101.17 \pm 52.84(31-209)$ & $84.19 \pm 50.29(25-198)$ & 0.168 & $93.73 \pm 52.08(25-209)$ \\
$\quad$ Parenteral & $45.88 \pm 16.14(17-95)$ & $57.31 \pm 24.39(25-144)$ & 0.019 & $50.89 \pm 20.82(17-144)$ \\
$\quad$ Oral & $55.29 \pm 47.40(0-166)$ & $26.84 \pm 41.10(0-126)$ & 0.009 & $42.82 \pm 46.66(0-166)$ \\
Incidence of using oral antibiotics & $31 / 41(75.6 \%)$ & $14 / 32,(43.8 \%)$ & 0.001 & $45 / 73(61.6 \%)$ \\
\hline
\end{tabular}

Data are presented as the mean \pm standard deviation or frequency, $C N$ culture negative, $C P$ culture positive, ${ }^{\#} p$ value between group $C N$ and $C P, p$ values of $<$ 0.05 were considered statistically significant

area of the infectious lesion. In multivariate logistic regression analysis, the presence of epidural abscess was the most powerful statistically significant predictor of causative bacterial identification. PVOs with epidural abscess were more likely to present neurological deficits such as leg pain or weakness. These may require a surgical treatment for removing epidural abscess to relieve neurological symptoms, which also allows obtaining a sufficient quantity of proper specimen, thus leading to increased microbiological diagnostic yield despite the use of empirical antibiotics in advance.

In laboratory data, the initial CRP level was significantly lower in the $\mathrm{CN}$ group than in the $\mathrm{CP}$ group. Previous studies reported fewer infectious signs and lower values of inflammatory markers in patients with culturenegative PVO, which may have been due to small inocula of pathogens $[11,13,18]$. Kim et al. [18] showed that culture-positive PVO is more likely to be associated with body temperature $\geq 37.8^{\circ} \mathrm{C}$, higher initial ESR and CRP, and the presence of paraspinal abscess. In this study, similar results were presented with a larger extent of the affected lesion, presence of epidural abscess, worse back pain, and higher initial CRP level in the CP group. Among the regimens of antibiotics, more frequent use of quinolone as an effective antibiotic in the $\mathrm{CN}$ group also supports these results. We performed serial follow-up of ESR, CRP, and VAS score of back pain. By the 3rd month, the CRP level had almost normalized and VAS scores had decreased by more than $50 \%$ of the initial scores. However, despite a tendency of continuous decline, the value of ESR remained consistently higher than normal. There were no statistically significant differences in ESR, CRP, and VAS score of back pain at 3 months between the two groups. We assume that the mechanical stress on the injured intervertebral disc and endplates as well as the restoration process of the PVO lesion, which may result in the persistent elevated ESR and VAS score of back pain. The values of ESR, CRP, and VAS score of back pain at the time of discontinuation of parenteral antibiotics or switching to oral antibiotics were $42.86 \pm$ $24.05 \mathrm{~mm} / \mathrm{h}, 0.91 \pm 1.18 \mathrm{mg} / \mathrm{dL}$, and $4.05 \pm 1.07$, respectively. There were no statistically significant differences between the two groups. We think that the values of ESR, CRP, and VAS score of back pain are meaningful and can help assess therapeutic response and decide regarding discontinuation of parenteral antibiotics or changing to oral antibiotics.

The recurrence rates reported in previous literatures have varied greatly. McHenry et al. [19] reported a recurrence rate of $14 \%$ in 253 patients, Park et al. [10] of $9.9 \%$ in 314 patients, and Kim et al. [18] of $6.6 \%$ in 151 patients. Unfortunately, data to guide the optimal duration of antibiotic therapy related to the recurrence of PVO are insufficient [7, 20-23]. Some studies reported that less than 6-8 weeks of antibiotic therapy may be associated with an increased risk of recurrence [18, 19, 24, 25]. Compared to the results of many previous literatures, our results showed relatively longer duration of

Table 5 Logistic regression analysis in the correlation between the causative bacterial identification (culture positive) and variable clinical variables

\begin{tabular}{|c|c|c|c|c|c|c|}
\hline \multirow[t]{2}{*}{ Clinical variable } & \multicolumn{3}{|c|}{ Univariate } & \multicolumn{3}{|c|}{ Multivariate } \\
\hline & OR & $95 \% \mathrm{Cl}$ & $p$ value & OR & $95 \% \mathrm{Cl}$ & $p$ value \\
\hline Open surgical biopsy & 3.31 & $1.26-8.71$ & 0.015 & & & \\
\hline Extent of affected lesion & 1.65 & $1.06-2.58$ & 0.027 & & & \\
\hline Epidural abscess & 6.90 & $2.22-21.49$ & 0.001 & 6.57 & $2.00-21.57$ & $0.002^{*}$ \\
\hline Initial CRP & 1.08 & $1.02-1.14$ & 0.009 & & & \\
\hline Initial back VAS & 2.00 & $1.21-3.33$ & 0.007 & 1.95 & $1.13-3.38$ & $0.017^{*}$ \\
\hline
\end{tabular}

$O R$ odds ratio, $C l$ confidential interval, CRP C-reactive protein (normal range $<0.5 \mathrm{mg} / \mathrm{dL}$ ), VAS visual analog scale, $p$ values of $<0.05$ were considered statistically significant 
Table 6 Changes of ESR/CRP and VAS score of back pain during 3 months since antimicrobial therapy started

\begin{tabular}{|c|c|c|c|c|}
\hline & CN group $(n=41)$ & CP group $(n=32)$ & $p$ value ${ }^{\#}$ & Total $(n=73)$ \\
\hline \multicolumn{5}{|l|}{ ESR } \\
\hline Initial (at diagnosis) & $66.88 \pm 31.89$ & $72.44 \pm 31.89$ & 0.462 & $69.32 \pm 31.79$ \\
\hline 1 week & $70.98 \pm 33.81$ & $74.31 \pm 26.84$ & 0.649 & $72.44 \pm 30.79$ \\
\hline 1 month & $55.29 \pm 29.94$ & $61.31 \pm 31.07$ & 0.405 & $57.93 \pm 30.37$ \\
\hline 3 months & $30.51 \pm 19.65^{+}$ & $42.81 \pm 31.44^{+}$ & 0.058 & $35.90 \pm 26.03$ \\
\hline \multicolumn{5}{|l|}{ CRP } \\
\hline Initial (at diagnosis)* & $9.21 \pm 7.43$ & $15.17 \pm 10.32$ & 0.005 & $11.83 \pm 9.24$ \\
\hline 1 week & $5.67 \pm 5.75$ & $6.97 \pm 5.74$ & 0.339 & $6.24 \pm 5.74$ \\
\hline 1 month & $1.89 \pm 2.05$ & $2.26 \pm 2.75$ & 0.516 & $2.06 \pm 2.37$ \\
\hline 3 months & $0.58 \pm 0.99^{+}$ & $0.79 \pm 1.29^{+}$ & 0.427 & $0.67 \pm 1.13$ \\
\hline \multicolumn{5}{|l|}{ VAS score of back pain } \\
\hline Initial (at diagnosis)* & $7.41 \pm 0.92$ & $8.13 \pm 1.13$ & 0.004 & $7.73 \pm 1.07$ \\
\hline 1 week & $5.73 \pm 1.18$ & $5.63 \pm 1.39$ & 0.724 & $5.68 \pm 1.27$ \\
\hline 1 month & $4.32 \pm 1.13$ & $4.47 \pm 1.27$ & 0.591 & $4.38 \pm 1.19$ \\
\hline 3 months & $3.37 \pm 0.92^{+}$ & $3.44 \pm 1.27^{+}$ & 0.780 & $3.39 \pm 1.08$ \\
\hline \multicolumn{5}{|c|}{ When discontinuation of parenteral antibiotics } \\
\hline ESR & $44.85 \pm 24.99$ & $40.31 \pm 22.91$ & 0.427 & $42.86 \pm 24.05$ \\
\hline CRP & $0.89 \pm 1.02$ & $0.93 \pm 1.37$ & 0.907 & $0.91 \pm 1.18$ \\
\hline VAS score of back pain & $3.98 \pm 1.08$ & $4.16 \pm 1.05$ & 0.476 & $4.05 \pm 1.07$ \\
\hline
\end{tabular}

$C N$ culture negative, $C P$ culture positive, ESR erythrocyte segmentation rate (normal range $<25 \mathrm{~mm} / \mathrm{h}$ ), $C R P$ C-reactive protein (normal range $<0.5 \mathrm{mg} / \mathrm{dL}$ ), $V A S$ visual analogue scale, ${ }^{\#} p$ value between group $\mathrm{CN}$ and $\mathrm{CP},{ }^{*}$ There is statistical significant difference between the two groups $(p<0.01){ }^{+}$, There is statistical significant difference compared to initial value $(p<0.01), p$ values of $<0.05$ were considered statistically significant

antibiotics and lower recurrence rate of $6.8 \%$. Kim et al. [18] reported a similar recurrence rate of $6.6 \%$ with an average of more than 100 days of the total antibiotics. Based on these results, we expect prolonged antibiotic therapy to be helpful in preventing recurrence. As mentioned above, culture-negative PVO shows fewer infectious signs and lower values of inflammatory markers, which may also be associated with a shorter duration of parenteral antibiotic therapy than in culture-positive PVO. However, as higher CRP level is usually associated with a higher risk of treatment failure in PVO, switching from parenteral antibiotics to oral antibiotics may be favorable in cases with lower CRP level $[18,26]$. We think that the assessment of therapeutic response based on laboratory data allows for shortening the duration of parenteral antibiotics and hospital stay with favorable outcomes, particularly, under an environment with low rates of causative bacterial identification. However, we could not clearly explain the reasons for the frequent use and longer duration of oral antibiotics in culturenegative PVO. Considering the similar recurrence rate between the two groups, oral antibiotics are expected to prevent the recurrence despite the relatively short period of parenteral antibiotics in culture-negative PVO.

There were several limitations in this study. First, it was a retrospective study with relatively small number of participants, which may have resulted in an underpowered statistical analysis. Second, the sample size of patients who experienced recurrence was small, and thus the statistical analysis of several factors related to recurrence was impossible. Third, false-positives in the assessment of the therapeutic response requiring additional antibiotic therapy could not be accurately identified, which could have led to the unnecessary use of antibiotics. To overcome these limitations, further studies with a larger number of participants under a prospective design are required.

\section{Conclusion}

Culture-negative PVO required a shorter duration of parenteral antibiotics and enabled changing to oral antibiotics compared to culture-positive PVO in terms of achieving similar outcomes. Discontinuation of parenteral antibiotics or switching to oral antibiotics can be considered based on the values of ESR, CRP, and VAS score for back pain. The presence of epidural abscess was the most significant factor for the identification of causative bacteria in PVO, which is associated with obtaining sufficient proper specimen via surgical culture. 


\section{Abbreviations}

PVO: Pyogenic vertebral osteomyelitis; ESR: Erythrocyte sedimentation rate; CRP: C-reactive protein; VAS: Visual analogue scale

\section{Acknowledgements}

Not applicable.

\section{Authors' contributions}

IJ and DY designed the study and drafted the manuscript. IJ, SWK, and DY analyzed clinical data. IJ was in charge of funding acquisition. All authors have read and approved the final manuscript.

\section{Funding}

This work was supported by the National Research Foundation (NRF) of Korea grant funded by the Korea government (MSIP; Ministry of Science, ICT \& Future Plan (2019M3E5D1A02068142).

\section{Availability of data and materials}

The datasets during and/or analysed during the current study are available from the corresponding author on reasonable request.

\section{Ethics approval and consent to participate}

All participants in this study were anonymized. The use of data from the hospital database for the analysis was approved by the institutional review board (Yeungnam University Hospital, 2020-06-091). Written informed consent was waived due to retrospective study design.

\section{Consent for publication}

Not applicable.

\section{Competing interests}

The authors declare that they have no competing interests.

Received: 12 July 2020 Accepted: 27 November 2020

Published online: 09 December 2020

\section{References}

1. Colmenero JD, Jimenez-Mejias ME, Sanchez-Lora FJ, Reguera JM, PalominoNicas J, Martos F, Garcia de las Heras J, Pachon J. Pyogenic, tuberculous, and brucellar vertebral osteomyelitis: a descriptive and comparative study of 219 cases. Ann Rheum Dis. 1997;56(12):709-15.

2. Issa K, Diebo BG, Faloon M, Naziri Q, Pourtaheri S, Paulino CB, Emami A. The epidemiology of vertebral osteomyelitis in the United States from 1998 to 2013. Clin Spine Surg. 2018;31(2):E102-8

3. Butler JS, Shelly MJ, Timlin M, Powderly WG, O'Byrne JM. Nontuberculous pyogenic spinal infection in adults: a 12-year experience from a tertiary referral center. Spine (Phila Pa 1976). 2006:31(23):2695-700.

4. Friedman JA, Maher CO, Quast LM, McClelland RL, Ebersold MJ. Spontaneous disc space infections in adults. Surg Neurol. 2002;57(2):81-6.

5. Sobottke R, Seifert H, Fatkenheuer G, Schmidt M, Gossmann A, Eysel P. Current diagnosis and treatment of spondylodiscitis. Dtsch Arztebl Int. 2008; 105(10):181-7.

6. Berbari EF, Kanj SS, Kowalski TJ, Darouiche RO, Widmer AF, Schmitt SK, Hendershot EF, Holtom PD, Huddleston PM 3rd, Petermann GW, et al. 2015 Infectious Diseases Society of America (IDSA) clinical practice guidelines for the diagnosis and treatment of native vertebral osteomyelitis in adults. Clin Infect Dis. 2015;61(6):e26-46.

7. Zimmerli W. Clinical practice. Vertebral osteomyelitis. N Engl J Med. 2010; 362(11):1022-9.

8. Park KH, Cho OH, Jung M, Suk KS, Lee JH, Park JS, Ryu KN, Kim SH, Lee SO, Choi $\mathrm{SH}$, et al. Clinical characteristics and outcomes of hematogenous vertebral osteomyelitis caused by gram-negative bacteria. J Inf Secur. 2014; 69(1):42-50

9. Jeon I, Kong E, Yu D, Hong CP. Clinical and radiological analysis of pyogenic vertebral osteomyelitis immediately after successful antimicrobial therapy: considerations for assessing therapeutic response. Diagnostics. 2020;10(11)

10. Park KH, Cho OH, Lee JH, Park JS, Ryu KN, Park SY, Lee YM, Chong YP, Kim $\mathrm{SH}$, Lee $\mathrm{SO}$, et al. Optimal duration of antibiotic therapy in patients with Hematogenous vertebral osteomyelitis at low risk and high risk of recurrence. Clin Infect Dis. 2016;62(10):1262-9.
11. Lora-Tamayo J, Euba G, Narvaez JA, Murillo O, Verdaguer R, Sobrino B, Narvaez J, Nolla JM, Ariza J. Changing trends in the epidemiology of pyogenic vertebral osteomyelitis: the impact of cases with no microbiologic diagnosis. Semin Arthritis Rheum. 2011:41(2):247-55.

12. Russo A, Graziano E, Carnelutti A, Sponza M, Cadeo B, Sartor A, Righi E, Bassetti M. Management of vertebral osteomyelitis over an eight-year period: the UDIPROVE (UDIne PROtocol on VErtebral osteomyelitis). Int J Infect Dis. 2019;89:116-21.

13. Bhagat S, Mathieson C, Jandhyala R, Johnston R. Spondylodiscitis (disc space infection) associated with negative microbiological tests: comparison of outcome of suspected disc space infections to documented nontuberculous pyogenic discitis. Br J Neurosurg. 2007;21(5):473-7.

14. de Lucas EM, Gonzalez Mandly A, Gutierrez A, Pellon R, Martin-Cuesta L, Izquierdo J, Sanchez E, Ruiz E, Quintana F. CT-guided fine-needle aspiration in vertebral osteomyelitis: true usefulness of a common practice. Clin Rheumatol. 2009;28(3):315-20.

15. Hassoun A, Taur $Y$, Singer C. Evaluation of thin needle aspiration biopsy in the diagnosis and management of vertebral osteomyelitis (VO). Int J Infect Dis. 2006:10(6):486-7.

16. Marschall J, Bhavan KP, Olsen MA, Fraser VJ, Wright NM, Warren DK. The impact of prebiopsy antibiotics on pathogen recovery in hematogenous vertebral osteomyelitis. Clin Infect Dis. 2011;52(7):867-72.

17. Rankine JJ, Barron DA, Robinson P, Millner PA, Dickson RA. Therapeutic impact of percutaneous spinal biopsy in spinal infection. Postgrad Med J. 2004;80(948):607-9.

18. Kim J, Kim YS, Peck KR, Kim ES, Cho SY, Ha YE, Kang Cl, Chung DR, Song JH. Outcome of culture-negative pyogenic vertebral osteomyelitis: comparison with microbiologically confirmed pyogenic vertebral osteomyelitis. Semin Arthritis Rheum. 2014;44(2):246-52.

19. McHenry MC, Easley KA, Locker GA. Vertebral osteomyelitis: long-term outcome for 253 patients from 7 Cleveland-area hospitals. Clin Infect Dis. 2002;34(10):1342-50.

20. Gouliouris T, Aliyu SH, Brown NM. Spondylodiscitis: update on diagnosis and management. J Antimicrob Chemother. 2010;65(Suppl 3):iii11-24.

21. Zarghooni K, Rollinghoff $M$, Sobottke R, Eysel P. Treatment of spondylodiscitis. Int Orthop. 2012;36(2):405-11.

22. Bernard L, Dinh A, Ghout I, Simo D, Zeller $V$, Issartel B, Le Moing $V$, Belmatoug N, Lesprit P, Bru JP, et al. Antibiotic treatment for 6 weeks versus 12 weeks in patients with pyogenic vertebral osteomyelitis: an open-label, non-inferiority, randomised, controlled trial. Lancet. 2015;385(9971):875-82

23. Lora-Tamayo J, Murillo O. Shorter treatments for vertebral osteomyelitis. Lancet. 2015:385(9971):836-7.

24. Roblot F, Besnier JM, Juhel L, Vidal C, Ragot S, Bastides F, Le Moal G, Godet C, Mulleman D, Azais I, et al. Optimal duration of antibiotic therapy in vertebral osteomyelitis. Semin Arthritis Rheum. 2007;36(5):269-77.

25. Grados F, Lescure FX, Senneville E, Flipo RM, Schmit UL, Fardellone P. Suggestions for managing pyogenic (non-tuberculous) discitis in adults. Joint Bone Spine. 2007;74(2):133-9.

26. Babouee Flury B, Elzi L, Kolbe M, Frei R, Weisser M, Scharen S, Widmer AF, Battegay $M$. Is switching to an oral antibiotic regimen safe after 2 weeks of intravenous treatment for primary bacterial vertebral osteomyelitis? BMC Infect Dis. 2014;14:226.

\section{Publisher's Note}

Springer Nature remains neutral with regard to jurisdictional claims in published maps and institutional affiliations.

Ready to submit your research? Choose BMC and benefit from:

- fast, convenient online submission

- thorough peer review by experienced researchers in your field

- rapid publication on acceptance

- support for research data, including large and complex data types

- gold Open Access which fosters wider collaboration and increased citations

- maximum visibility for your research: over $100 \mathrm{M}$ website views per year

At BMC, research is always in progress.

Learn more biomedcentral.com/submissions 